Article

\title{
Integration of Multifocal Microlens Array on Silicon Microcantilever via Femtosecond-Laser-Assisted Etching Technology
}

\author{
Bao-Xu Wang, Jia-Xin Zheng, Jin-Yong Qi, Ming-Rui Guo, Bing-Rong Gao and Xue-Qing Liu *CD
}

check for

updates

Citation: Wang, B.-X.; Zheng, J.-X.;

Qi, J.-Y.; Guo, M.-R.; Gao, B.-R.;

Liu, X.-Q. Integration of Multifocal

Microlens Array on Silicon

Microcantilever via

Femtosecond-Laser-Assisted Etching

Technology. Micromachines 2022, 13,

218. https://doi.org/10.3390/

mi13020218

Academic Editors: Benny C. F. Cheung and Jiang Guo

Received: 31 December 2021

Accepted: 28 January 2022

Published: 29 January 2022

Publisher's Note: MDPI stays neutral with regard to jurisdictional claims in published maps and institutional affiliations.

Copyright: (C) 2022 by the authors. Licensee MDPI, Basel, Switzerland. This article is an open access article distributed under the terms and conditions of the Creative Commons Attribution (CC BY) license (https:// creativecommons.org/licenses/by/ $4.0 /)$.

\begin{abstract}
State Key Laboratory of Integrated Optoelectronics, College of Electronic Science and Engineering, Jilin University, Changchun 130012, China; bxwang_sklio@jlu.edu.cn (B.-X.W.); zhengjx21@mails.jlu.edu.cn (J.-X.Z.); qijy20@mails.jlu.edu.cn (J.-Y.Q.); guomr21@mails.jlu.edu.cn (M.-R.G.); brgao@jlu.edu.cn (B.-R.G.)

* Correspondence: liuxueqing@jlu.edu.cn
\end{abstract}

\begin{abstract}
Micro-opto-electromechanical systems (MOEMSs) are a new class of integrated and miniaturized optical systems that have significant applications in modern optics. However, the integration of micro-optical elements with complex morphologies on existing micro-electromechanical systems is difficult. Herein, we propose a femtosecond-laser-assisted dry etching technology to realize the fabrication of silicon microlenses. The size of the microlens can be controlled by the femtosecond laser pulse energy and the number of pulses. To verify the applicability of this method, multifocal microlens arrays (focal lengths of 7-9 $\mu \mathrm{m}$ ) were integrated into a silicon microcantilever using this method. The proposed technology would broaden the application scope of MOEMSs in three-dimensional imaging systems.
\end{abstract}

Keywords: MOEMS; silicon microcantilever; multifocal microlens array; femtosecond laser; dry etching

\section{Introduction}

Micro-opto-electromechanical systems (MOEMSs) are a new class of micro-systems that integrate micro-optical devices and micro-electromechanical systems (MEMSs); thus, they can simultaneously realize mechanical, electrical, and optical functions [1,2]. With the characteristics of high integration, miniaturizability and accurate control, MOEMSs have great potential applications in optical communication, micro sensing and optical imaging, among others [3-5]. Owing to the limitations of fabrication technology, a micro-mirror is the most commonly used micro-optical element in MOEMSs. For example, digital micro-mirror devices are widely used as MOEMS devices in modern optics for digital optical control. To impart more functions in and expand the application scope of MOEMSs, more forms of micro-optical devices need to be integrated with MEMSs, for example, the integration of microlens on MEMS that acts as the optical scanner has wide applications in optical imaging [6,7].

As a basic component in the field of micro-optics, microlenses can realize the properties of focusing, imaging, and beam shaping. Moreover, compared with a single microlens, microlens arrays in integrated systems can obtain information on the multiple positions and angles of images [8-11]. Therefore, microlens arrays are used in optical applications, including color imaging systems [12], 3D image acquisition systems [13] and fingerprint identification systems [14]. Typically, each microlens in an array has the same size; thus, the focal length of the microlens is the same. Therefore, microlens arrays can only image objects on their common focal plane, resulting in small field-of-view angles and a low depth of field. Based on the properties of microlenses with different focal lengths, the multifocal microlens array can solve the above-mentioned problems, and hence can be applied in 3D imaging systems [15-19]. It is difficult to integrate the above-mentioned micro-optical elements with a complicated morphology and existing MEMSs, e.g., focused ion beam 
technology can remove materials atom by atom. Thus, high-precision micro/nanostructures can be realized using this technology. Generally, the incident ions only work in the thickness range of several atomic layers on the surface; therefore, the fabrication efficiency of this technology is very low. Photolithography is another common technique used for fabricating micro/nanostructures; however, it has a high requirement for flatness of the sample surface. Therefore, integration of complicated micro-optical elements and MEMS devices is difficult using photolithography. To overcome this, a feasible technology that realizes the integration of micro-optical elements with complicated morphologies and existing MEMSs must be developed.

Femtosecond laser processing [20-22] has been widely used to fabricate various types of micro-optical elements because of its ultra-high-precision, mask-free procedure, and in situ processing [23]. However, it has induced high surface roughness in the integration of micro-optical elements and MEMSs of hard materials owing to direct femtosecond laser ablation. In this paper, we proposed a femtosecond-laser-assisted dry etching technology to integrate a multifocal microlens array on the surface of silicon microcantilever, which realizes the integration of micro-optical devices and MEMS devices. A point on the surface of the microcantilever was modified by femtosecond laser, and the modified region was etched and expanded to a microlens via inductively coupled plasma (ICP) etching. Owing to the high degree of freedom of femtosecond laser processing and the effective reduction of surface roughness by dry etching, the fabrication efficiency of microlens arrays with high surface quality at any position on the surface of the silicon microcantilever can be realized. Moreover, a multifocal microlens array was fabricated by adjusting the modification degree of the materials, which can be realized through the adjustment of the laser parameters. Compared with the traditional microlens array, the multifocal microlens array can effectively resolve the problems of capturing 3D image depth of field and numerical aperture in a 3D integral imaging system.

\section{Materials and Methods}

First, undoped silicon wafers were cleaned with acetone, ethanol, and deionized water for $30 \mathrm{~min}$ to obtain a clean surface. The femtosecond laser $(343 \mathrm{~nm}, 200 \mathrm{kHz}$, 280 fs (Light Conversion Pharos, Vilnius, Lithuania)) is tightly focused through a high numerical aperture objective lens $(\mathrm{NA}=0.95,40 \times)$ and matched with a three-dimensional piezoelectric platform (the strokes of the $x$ - and $y$-axes are $1.5 \mathrm{~mm}$, that of the $z$-axis is $100 \mu \mathrm{m}$, and accuracy is $1 \mathrm{~nm}$ ) to realize the preparation of micro/nanostructures on the silicon surface [24-29]. In addition, the femtosecond laser can also be used to process other materials via multi-photon absorption, for example, lift off $\mathrm{GaN}$ [30,31]. After femtosecond laser treatment, a laser-modified region was formed on the silicon surface, changing its physical and chemical properties. Here, the femtosecond laser was used to change the etching rate in a local region with a generation of amorphous and polycrystalline phases, and composition change $[23,32]$. Then, the silicon sample was etched via ICP (ICP-100A, Tailong Electronics, Beijing, China) with $\mathrm{SF}_{6}$ gas at the flow rate of $80 \mathrm{sccm}$, with the upper electrode power of $500 \mathrm{~W}$, and a lower electrode power of $100 \mathrm{~W}$. In the initial time of the dry etching process, the etching rate of the laser-modified area was greater than that of the unmodified area, and the modified area first etched round holes. With the further progress of etching, owing to the influence of isotropic etching, we can expand outward through the circular hole to obtain a silicon-based microlens with a smooth surface (Figure 1). The surface roughness can be decreased to about $5.56 \mathrm{~nm}$ (Figure 2), obtained by measuring the bottom of the microlens. 


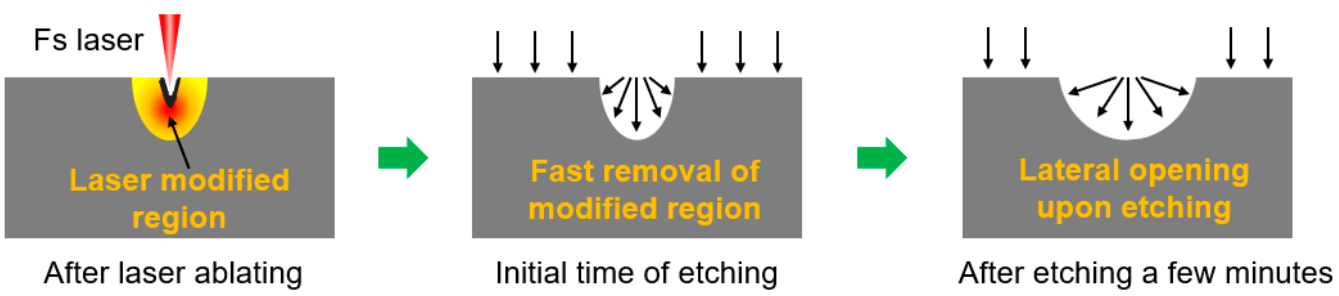

Figure 1. Schematic diagram of fabrication of silicon microlens by femtosecond laser modification with subsequent etching.

$927.2 \mathrm{~nm}$

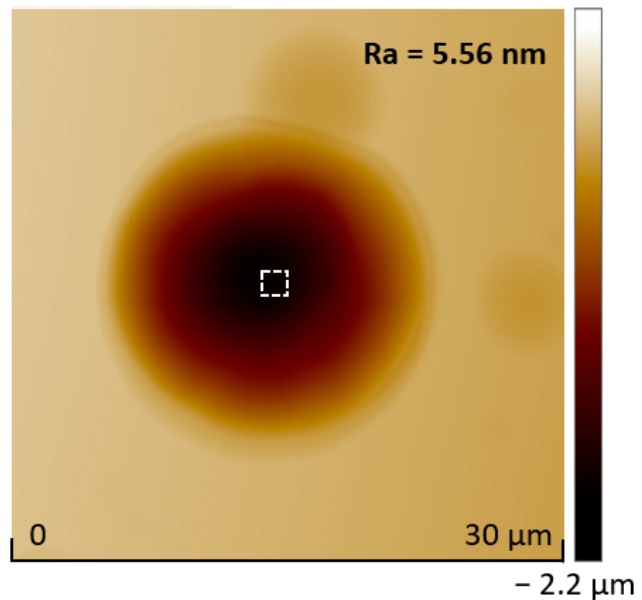

Figure 2. Atomic force microscopy (AFM) image of a silicon microlens fabricated by femtosecond laser modification with subsequent etching.

\section{Results and Discussions}

\subsection{Preparation of Microlens}

The dry etching rate of the modified region formed by the femtosecond laser is related to the degree of modification [33-35]. By adjusting parameters, such as the power of the femtosecond laser and the number of femtosecond laser pulses, regions with different degrees of modification can be realized. Based on this, we fabricated the microlens arrays with different diameters and depths on silicon wafers. According to the scanning electron microscopy (SEM) result (Figure 3a) and the cross-sectional view of the microlens array (Figure $3 b, c$ ), this method can realize the controllable preparation of microlenses with different structural parameters. The actual size of the lens changes periodically according to the experimental expectation, and the lens surface is smooth.
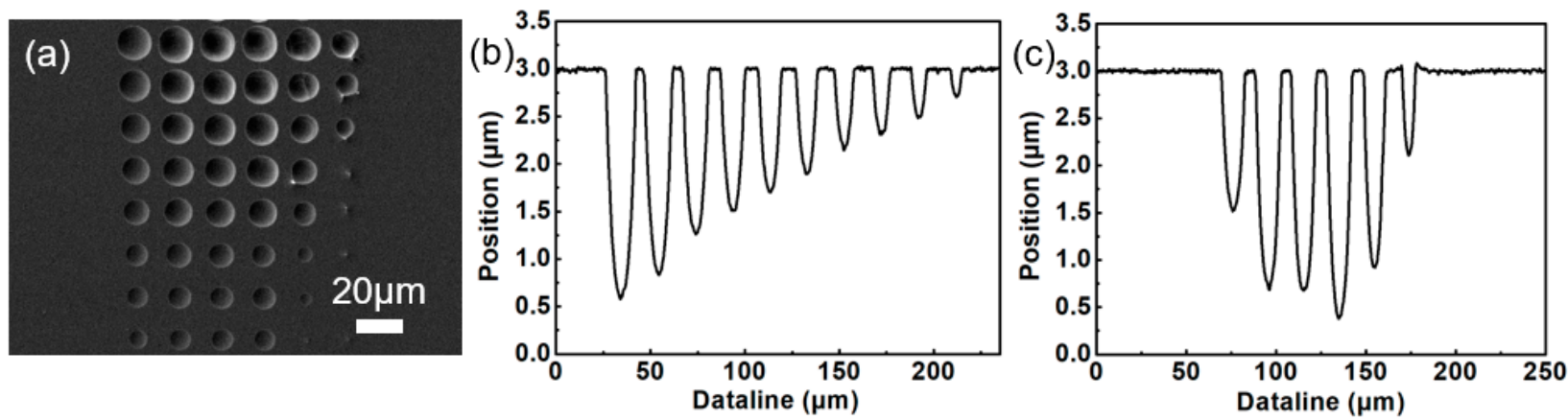

Figure 3. (a) Scanning electron microscopy (SEM) images of the multi-focus microlens array; (b) Crosssectional profiles with the depth of lens from (b) deep to shallow, and (c) shallow to deep and then to shallow. 
From further analysis of the effect of the laser on the etching morphology of the silicon-based microlens, the conclusions are as follows:

(a) Because the modified area increases with the laser power, the size of the silicon-based microlens increases after the ICP etching process. The diameter and depth of the silicon-based microlens showed an increasing trend as the power of the femtosecond laser increased, as shown in Figure 4a. By calculating the diameter and depth of the silicon-based concave microlens under different laser powers, the corresponding radius of curvature was obtained. The relationship between the radius of curvature and laser power is presented in Figure $4 \mathrm{~b}$.

(b) With an increase in the laser pulse number, the diameter and depth of the silicon-based concave microlens first increased and then decreased (Figure $4 \mathrm{c}$ ). This is because the silicon surface would react with oxygen in the air with a greater number of laser pulses, generating a passivation layer on the silicon surface and preventing the etching progress. Therefore, the size of the silicon-based concave microlens decreased with an increase in the number of laser pulses. The different diameters and depths of the silicon-based concave microlens can be obtained by controlling the pulse numbers of the laser. The radius of curvature gradually decreased as the number of pulses increased, as shown in Figure $4 \mathrm{~d}$.

(c) The focal lengths of the microlenses with varying radii of curvature also differ. The experimental results show that the size of the silicon-based concave microlens can be flexibly adjusted by changing the femtosecond laser power and pulse number, and the controllable preparation of microlenses with different focal lengths can be realized.

(a)

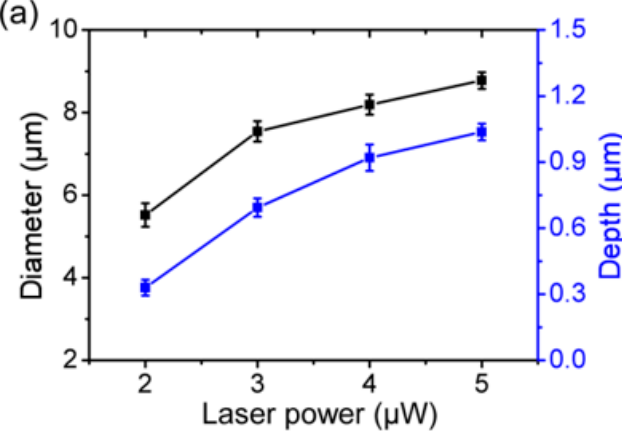

(c)

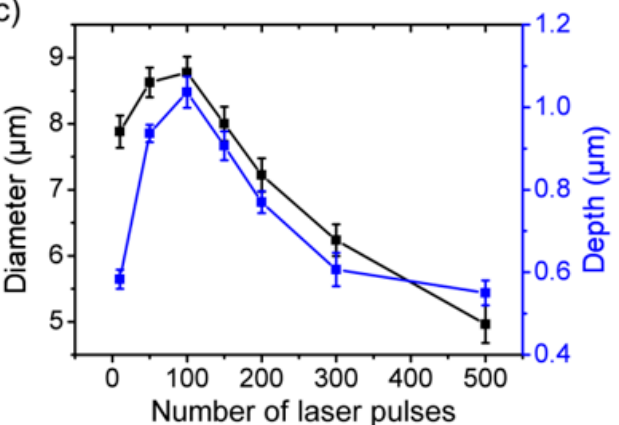

(b)

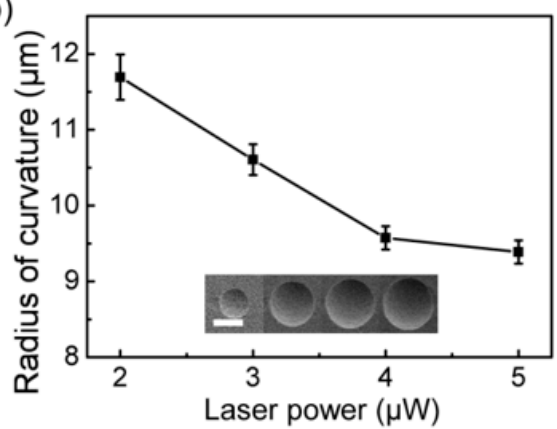

(d)

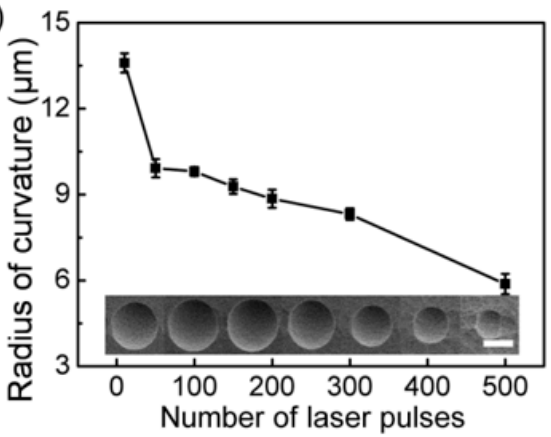

Figure 4. Relationship between the depth and the diameter of structures after etching with (a) laser power and (c) number of laser pulses. Relationship between the radius of structures after etching with (b) laser power and (d) number of laser pulses.

The energy around the laser focus is different and conforms to a gaussian distribution [36-38]. Therefore, the degree of the modification region can be affected by the different positions of the focus. The focus position of the silicon surface can be controlled by the movement of the three-dimensional piezoelectric mobile platform, which helps to study the influence of the focus position on the morphology of the microlens after etching. In the experiment, the processing of different laser focus positions was realized by controlling the depth of the silicon sample table. First, the processing was conducted at the laser 
focus, and gradually deviated from the focus with the processing from inside to outside, and then the circular silicon-based microlens array was obtained via ICP etching. From the SEM image displayed in Figure 5a, the diameter of the final silicon-based concave microlens decreased gradually with the shift in the focus. The atomic force microscope (AFM) image of the silicon-based microlens array in Figure 5b indicates that the depth of the prepared silicon-based concave microlens gradually decreased as the focused energy decreased. A cross-sectional profile of the silicon-based microlens array is shown in Figure 5c. The depth of the silicon-based concave microlens gradually decreased as the focused energy decreased and the processing proceeded outward. The depth of the siliconbased concave microlens was maximum when the silicon surface was at the maximum focus energy, and the depth of the concave microlens gradually decreased with the focus shift (Figure 5d).

(a)

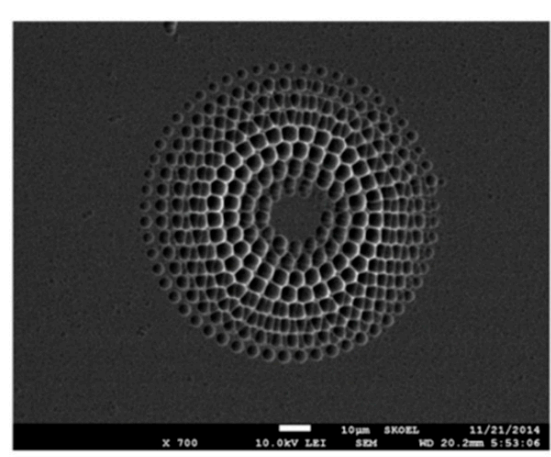

(c)

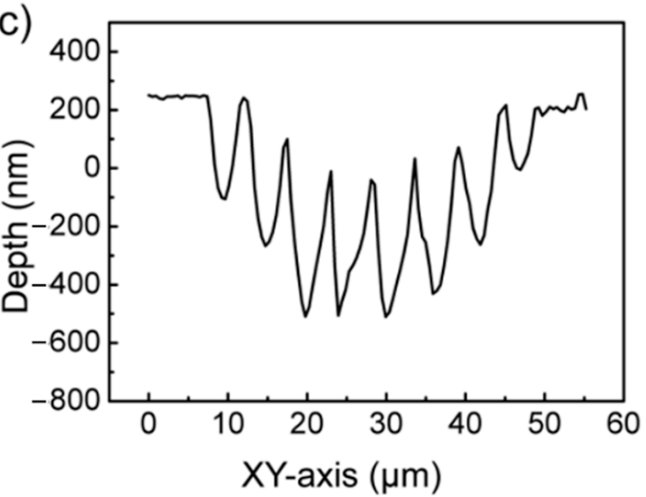

(b)

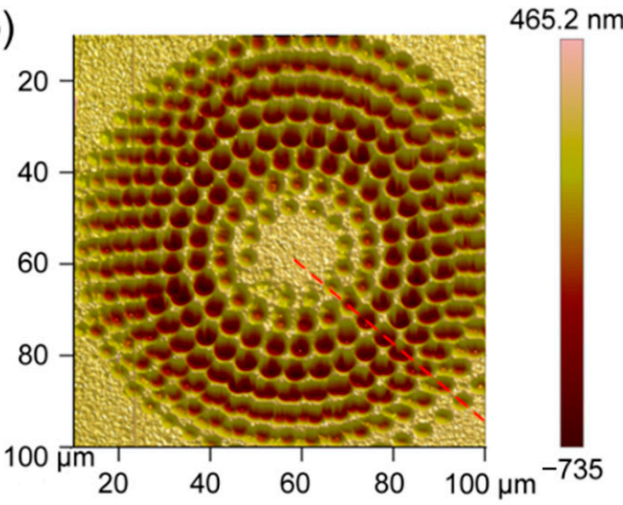

(d)

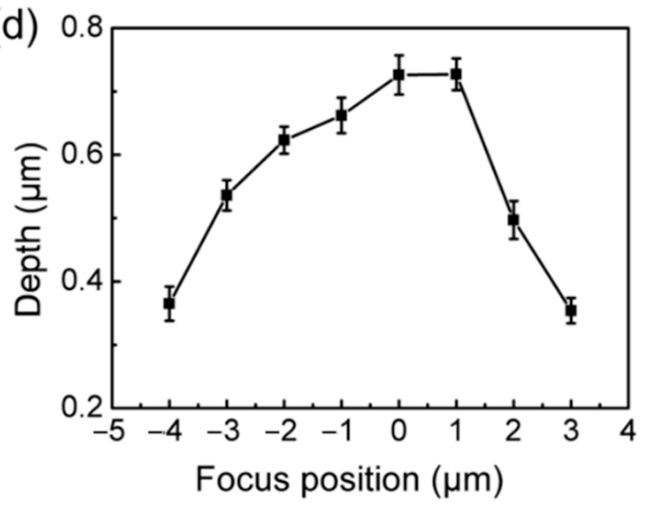

Figure 5. (a) SEM and (b) AFM images of the concave microlens arrays with different laser focus heights. (c) The cross-sectional profile of the concave microlens array. (d) Relationship between the depth of the concave microlens array with the laser focus position.

For silicon with different crystal orientations, anisotropy is often observed due to different crystal orientations in the process of wet etching. This leads to an irregular shape when etching a circular structure. To verify the effect of crystal orientation on the etching effect, we replaced silicon wafers with different crystal orientations for the experiments (Figure 6). It was found that the depths of the silicon-based concave microlenses prepared using silicon with three crystal orientations are basically the same, i.e., the morphology of the microlens is not significantly dependent on the silicon crystal orientation. This is because the principle of dry etching involves using the plasma of chemical gas to produce a chemical reaction, and accelerate physical etching and chemical etching through an electric field, so the etching is isotropic. It should be mentioned that by changing the etching gas in the cycle during the etching process, high-aspect-ratio silicon microstructures can be realized [39,40]. Therefore, different patterned silicon-based microlens arrays can be prepared using this method. 


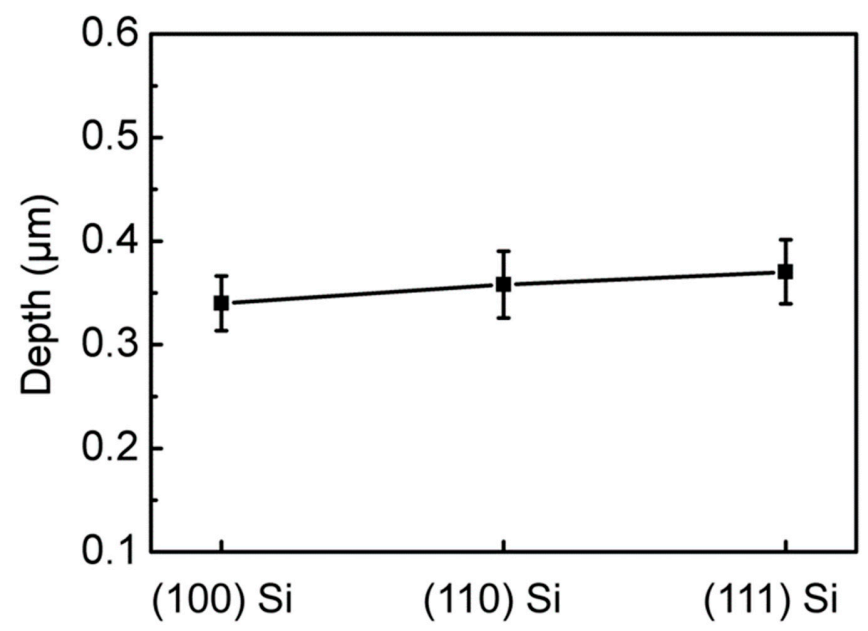

Figure 6. Relationship between the depth of the silicon microlens after etching and three types of silicon with different crystal orientations.

\subsection{Microlens Array Fabrication}

Femtosecond laser processing has a high degree of freedom, which can plan the trajectory of light spots and then realize the preparation of arbitrary patterned structures. In the experiment, two types of silicon-based microlens arrays were prepared by controlling the movement of a three-dimensional platform. First, the silicon wafer was ablated by a femtosecond laser to form a rectangular arrangement and a honeycomb dense arrangement lattice. Then, the silicon wafer processed using the femtosecond laser was etched via ICP. Owing to the use of the same laser parameters, the modification degree of each part was the same, thus two groups of microlens arrays with the same size and good morphology were formed after dry etching. The two silicon-based microlens arrays were characterized via SEM; the SEM images are shown in Figure 7a,b. Finally, the optical properties of the rectangular array microlens were characterized, as shown in Figure 7c,d. Thus, the siliconbased lens array has good focusing and imaging effects.
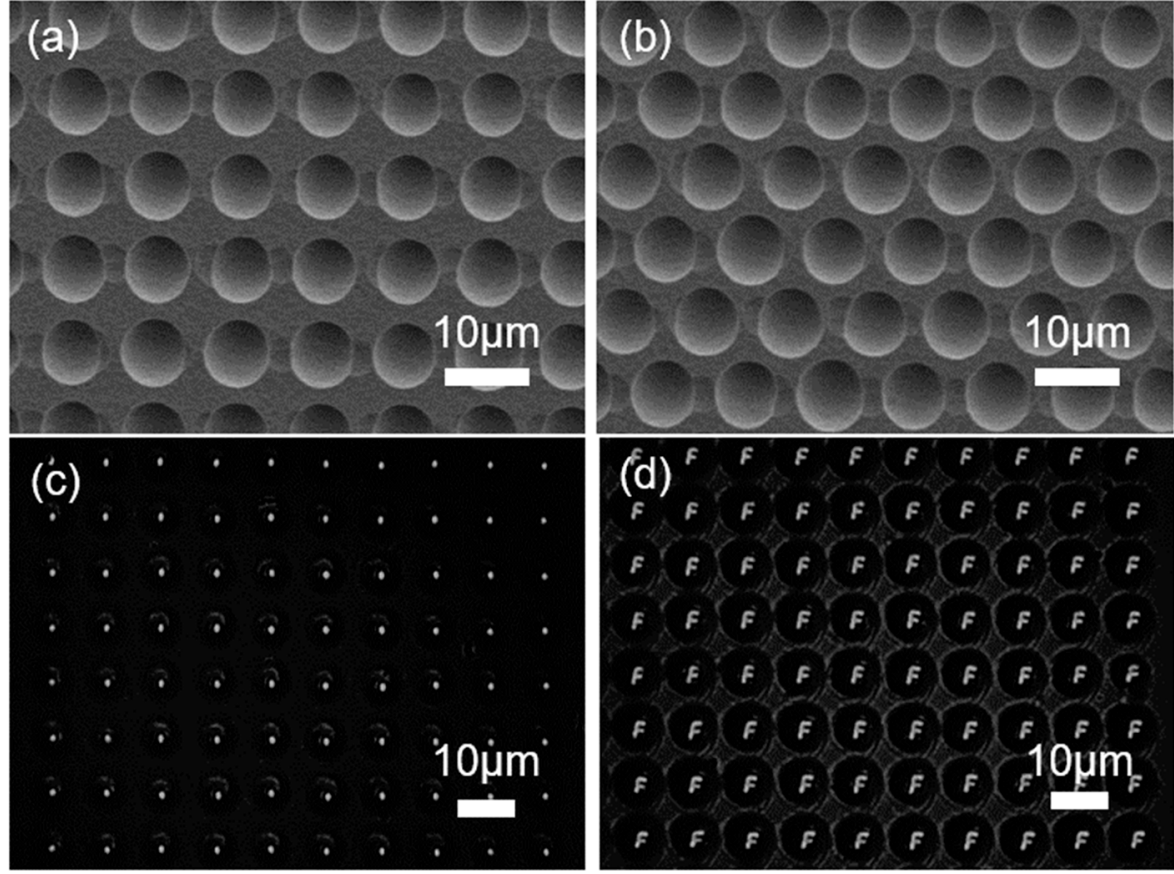

Figure 7. SEM images of (a) rectangular microlens array and (b) hexagonal microlens array. (c) Focal spots and (d) optical performance of the hexagonal microlens array. 
In addition to the above regular microlens array, an arbitrary arrangement of microlenses with inconsistent structures and sizes can be realized by adjusting the laser parameters and scanning path in the experiment. Through this method, some other specific microlenses were fabricated, such as Chinese knots, petals, and hidden letters, as displayed in Figure 8a-c. The corresponding SEM images obtained after etching each pattern are shown in Figure 8d-f. It is difficult to distinguish the final designed microlens array from the laser-modified pattern. After etching, microlenses of different sizes were formed to realize a clear pattern. In particular, the letters "JLU" were difficult to observe after laser modification. Following etching, the hidden letters can be clearly seen by the distinction of the microlens diameter.

\subsection{Multifocal Microlens Array Integration on Silicon Cantilever}

Femtosecond lasers have the characteristics of local in situ processing and micro nanostructure preparation at any position of a nonplanar structure. Therefore, we can use this method to realize the controllable preparation of a microlens array on a silicon microcantilever. By adjusting the position of the light spot and the degree of modification, we fabricated microlens arrays of different sizes on a silicon microcantilever (Figure 9a). The size of the lens determines its focal length, and its basic relationship satisfies the following equation:

$$
\begin{gathered}
R=\frac{h^{2}+r^{2}}{2 h} \\
f=-\frac{R}{2}
\end{gathered}
$$

where $r$ and $h$ are the radius and depth of the microlens, respectively; $R$ is the radius of curvature of the microlens, and $f$ is the focal length of the microlens. According to Equations (1) and (2), the focal lengths of the leftmost and rightmost microlenses were 7 and $9 \mu \mathrm{m}$, respectively. Figure $9 \mathrm{~b}$ presents the cross-sectional characterization curve of the multifocal microlens array. Because of the different focal lengths of the microlenses, the focus morphology and imaging effect also differ at different positions. The focusing and imaging of the lens arrays at different focus positions are depicted in Figure $9 c-f$. When the large lens is at the focus, the focus and imaging of the rear small lens are unclear. Contrarily, when the small lens is in focus, the large lens will be out of focus. A multifocal microlens array was successfully fabricated on a silicon microcantilever, enabling the integration of micro-optical devices and MEMSs.
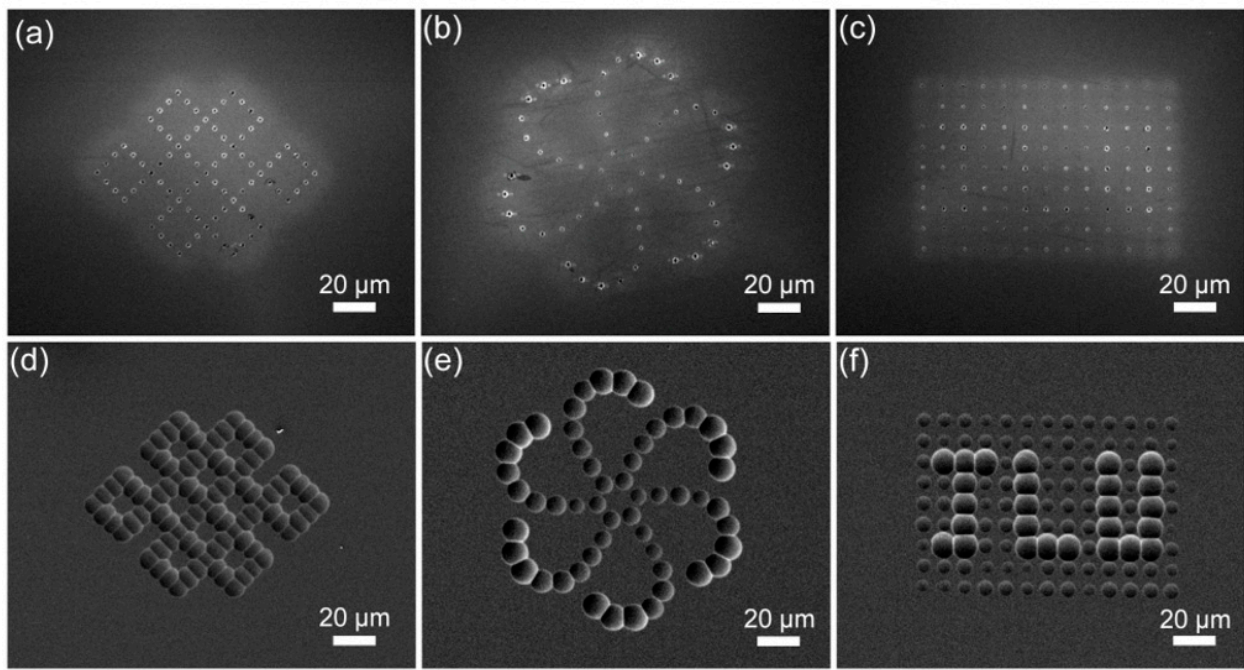

Figure 8. SEM images of (a) Chinese knot, (b) petal, and (c) letters "JLU" before etching; and (d) Chinese knot, (e) petal, and (f) letters "JLU" after etching. 

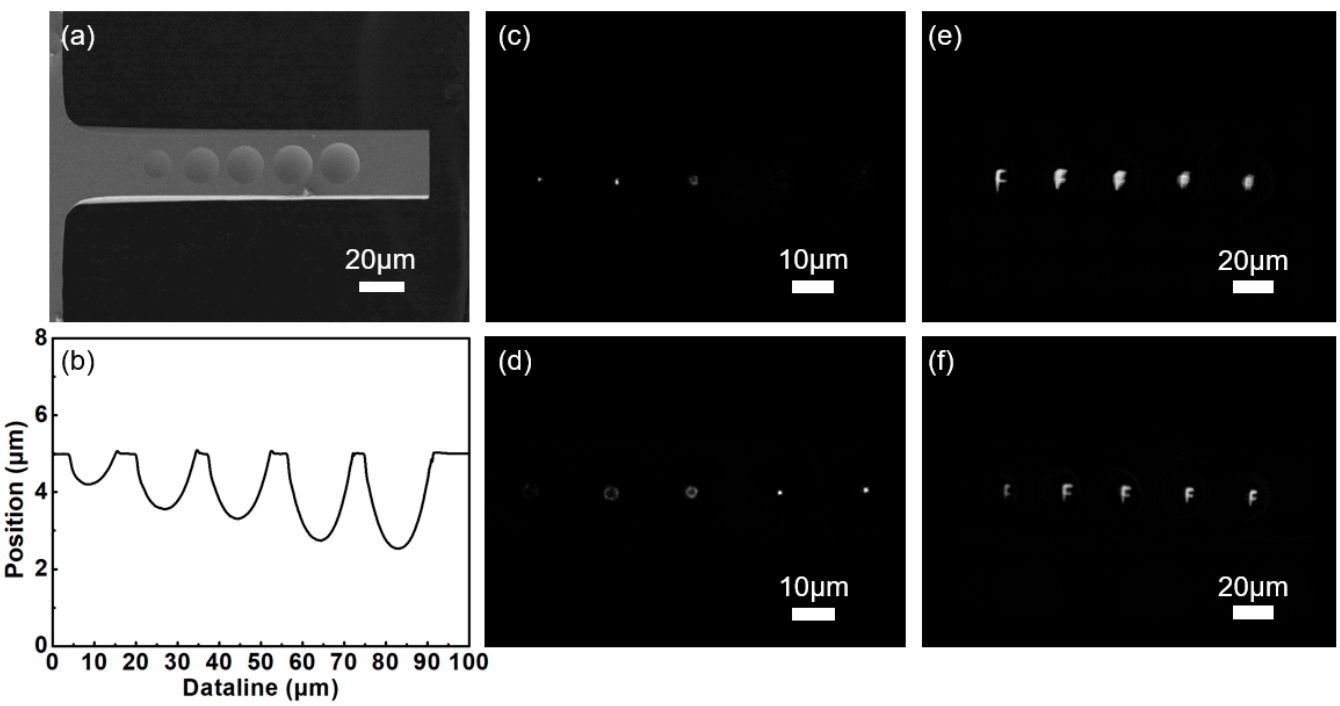

Figure 9. (a) SEM image of the silicon-cantilever-integrated multi-focus microlens array. (b) The crosssectional profile of the multi-focus microlens array. $(\mathbf{c}, \mathbf{d})$ Focal spots at different focal locations of the multi-focus microlens array. (e,f) Optical performance at different focal locations of the multi-focus microlens array.

\section{Conclusions}

In summary, we investigated the effects of femtosecond laser power and pulse number on the structure of a microlens after etching. It was found that the curvature of the siliconbased concave microlens decreased with an increase in the laser power. With an increase in the number of laser pulses, the diameter and depth of the silicon-based concave microlens first increased and then decreased. The effects of focus change and silicon crystal orientation on the final effect of the experiment were studied. It was found that when the silicon surface is at the maximum focus energy, the depth of the silicon-based concave microlens is at its maximum. With the gradual shift in focus, the depth of the concave microlens gradually decreases. The degree of modification of the laser is unrelated to the crystal direction of silicon. Uniform lens arrays with different arrangements and microlens arrays with arbitrary shapes and sizes were established on the silicon surface. Finally, a multifocal microlens array was fabricated on a silicon microcantilever. Meanwhile, the focusing and imaging effects of the 7 and $9 \mu \mathrm{m}$ microlenses at different positions were compared. The integration of micro-optical components and MEMSs was realized, providing potential applications for silicon-based MEMSs in the fields of optical communications, digital image processing and biomedicine.

Author Contributions: Conceptualization, X.-Q.L. and B.-R.G.; methodology, B.-X.W., X.-Q.L., B.-R.G. and J.-X.Z.; formal analysis, B.-X.W., J.-X.Z. and J.-Y.Q.; investigation, B.-X.W., J.-X.Z., J.-Y.Q. and M.R.G.; data curation, X.-Q.L. and J.-X.Z.; writing—original draft preparation, B.-X.W.; writing—review and editing, B.-X.W. and J.-X.Z.; visualization, B.-X.W., J.-X.Z. and M.-R.G.; supervision, X.-Q.L. All authors have read and agreed to the published version of the manuscript.

Funding: This work was supported by the Strategic Priority Research Program of CAS (Grant No. XDC07030303) and the National Natural Science Foundation of China (NSFC, Grant Nos. 62105117, 61960206003, 61825502 and 61805100).

Institutional Review Board Statement: Not applicable.

Data Availability Statement: Not applicable.

Conflicts of Interest: The authors declare no conflict of interest. 


\section{References}

1. Lu, Q.; Wang, Y.; Wang, X.; Yao, Y.; Wang, X.; Huang, W. Review of micromachined optical accelerometers: From mg to sub-mu g. Opto-Electron. Adv. 2021, 4, 200045. [CrossRef]

2. Joshi, P.K. Recent Development in Applications of Optical MEMS: A Review. Helix 2018, 8, 4345-4348. [CrossRef]

3. Tortschanoff, A.; Lenzhofer, M.; Frank, A.; Wildenhain, M.; Sandner, T.; Schenk, H.; Scherf, W.; Kenda, A. Position encoding and phase control of resonant MOEMS mirrors. Sens. Actuators A Phys. 2010, 162, 235-240. [CrossRef]

4. Shao, Y.; Dickensheets, D.L. MOEMS 3-D scan mirror for single-point control of beam deflection and focus. J. Microlith. Microfab. 2005, 4, 041502. [CrossRef]

5. Erdmann, L.; Deparnay, A.; Maschke, G.; Langle, M.L.; Brunner, R. MOEMS-Based lithography for the fabrication of micro-optical components. J. Microlith. Microfab. 2005, 4, 041601. [CrossRef]

6. Toshiyoshi, H.; Su, G.-J.; LaCosse, J.; Wu, M.C. A surface micromachined optical scanner array using photoresist lenses fabricated by a thermal reflow process. J. Lightwave Techol. 2003, 21, 1700-1708. [CrossRef]

7. Kwon, S.; Lee, L.P. Stacked Two Dimensional Microlens Scanner for Micro Confocal Imaging Array. In Proceedings of the Fifteenth IEEE International Conference on Micro Electro Mechanical Systems (Cat. No. 02CH37266), Las Vegas, NV, USA, 24 January 2002; pp. 483-486.

8. $\quad$ Ersumo, N.T.; Yalcin, C.; Antipa, N.; Pegard, N.; Waller, L.; Lopez, D.; Muller, R. A micromirror array with annular partitioning for high-speed random-access axial focusing. Light Sci. Appl. 2020, 9, 183. [CrossRef] [PubMed]

9. Fan, Z.-B.; Qiu, H.-Y.; Zhang, H.-L.; Pang, X.-N.; Zhou, L.-D.; Liu, L.; Ren, H.; Wang, Q.-H.; Dong, J.-W. A broadband achromatic metalens array for integral imaging in the visible. Light Sci. Appl. 2019, 8, 67. [CrossRef]

10. Zhao, R.; Huang, L.; Wang, Y. Recent advances in multi-dimensional metasurfaces holographic technologies. PhotoniX 2020, 1, 20. [CrossRef]

11. Zou, X.; Zheng, G.; Yuan, Q.; Zang, W.; Chen, R.; Li, T.; Li, L.; Wang, S.; Wang, Z.; Zhu, S. Imaging based on metalenses. PhotoniX 2020, 1, 2. [CrossRef]

12. Tanida, J.; Shogenji, R.; Kitamura, Y.; Yamada, K.; Miyamoto, M.; Miyatake, S. Color imaging with an integrated compound imaging system. Opt. Express 2003, 11, 2109-2117. [CrossRef] [PubMed]

13. Horisaki, R.; Irie, S.; Ogura, Y.; Tanida, J. Three-Dimensional information acquisition using a compound imaging system. Opt. Rev. 2007, 14, 347-350. [CrossRef]

14. Shogenji, R.; Kitamura, Y.; Yamada, K.; Miyatake, S.; Tanida, J. Bimodal fingerprint capturing system based on compound-eye imaging module. Appl. Opt. 2004, 43, 1355-1359. [CrossRef] [PubMed]

15. Zhou, X.T.; Peng, Y.Y.; Peng, R.; Zeng, X.Y.; Zhang, Y.A.; Guo, T.L. Fabrication of Large-Scale Microlens Arrays Based on Screen Printing for Integral Imaging 3D Display. ACS Appl. Mater. Interfaces 2016, 8, 24248-24255. [CrossRef] [PubMed]

16. Bae, S.I.; Kim, K.; Yang, S.; Jang, K.W.; Jeong, K.H. Multifocal microlens arrays using multilayer photolithography. Opt. Express 2020, 28, 9082-9088. [CrossRef]

17. Lee, J.H.; Chang, S.; Kim, M.S.; Kim, Y.J.; Kim, H.M.; Song, Y.M. High-Identical Numerical Aperture, Multifocal Microlens Array through Single-Step Multi-Sized Hole Patterning Photolithography. Micromachines 2020, 11, 1068. [CrossRef] [PubMed]

18. Lian, G.G.; Liu, Y.S.; Tao, K.K.; Xing, H.M.; Huang, R.X.; Chi, M.B.; Zhou, W.C.; Wu, Y.H. Fabrication and Characterization of Curved Compound Eyes Based on Multifocal Microlenses. Micromachines 2020, 11, 854. [CrossRef]

19. Park, M.K.; Lee, H.J.; Park, J.S.; Kim, M.; Bae, J.M.; Mahmud, I.; Kim, H.R. Design and Fabrication of Multi-Focusing Micro lens Array with Different Numerical Apertures by using Thermal Reflow Method. J. Opt. Soc. Korea 2014, 18, 71-77. [CrossRef]

20. Li, Z.-Z.; Wang, L.; Fan, H.; Yu, Y.-H.; Chen, Q.-D.; Juodkazis, S.; Sun, H.-B. O-FIB: Far-Field-Induced near-field breakdown for direct nanowriting in an atmospheric environment. Light Sci. Appl. 2020, 9, 41. [CrossRef]

21. Wang, H.; Zhang, Y.-L.; Han, D.-D.; Wang, W.; Sun, H.-B. Laser fabrication of modular superhydrophobic chips for reconfigurable assembly and self-propelled droplet manipulation. PhotoniX 2021, 2, 17. [CrossRef]

22. Yin, D.; Feng, J.; Ma, R.; Liu, Y.F.; Zhang, Y.L.; Zhang, X.L.; Bi, Y.G.; Chen, Q.D.; Sun, H.B. Efficient and mechanically robust stretchable organic light-emitting devices by a laser-programmable buckling process. Nat. Commun. 2016, 7, 11573. [CrossRef] [PubMed]

23. Liu, X.-Q.; Bai, B.-F.; Chen, Q.-D.; Sun, H.-B. Etching-Assisted femtosecond laser modification of hard materials. Opto-Electron. Adv. 2019, 2, 19002101-19002114. [CrossRef]

24. Fang, H.H.; Yang, J.; Ding, R.; Chen, Q.D.; Wang, L.; Xia, H.; Feng, J.; Ma, Y.G.; Sun, H.B. Polarization dependent two-photon properties in an organic crystal. Appl. Phys. Lett. 2010, 97, 101101. [CrossRef]

25. Sun, Y.L.; Dong, W.F.; Yang, R.Z.; Meng, X.; Zhang, L.; Chen, Q.D.; Sun, H.B. Dynamically Tunable Protein Microlenses. Angew. Chem. Int. Ed. 2012, 51, 1558-1562. [CrossRef]

26. Jiang, H.B.; Zhang, Y.L.; Han, D.D.; Xia, H.; Feng, J.; Chen, Q.D.; Hong, Z.R.; Sun, H.B. Bioinspired Fabrication of Superhydrophobic Graphene Films by Two-Beam Laser Interference. Adv. Funct. Mater. 2014, 24, 4595-4602. [CrossRef]

27. Feng, T.; Chen, G.; Han, H.; Qiao, J. Femtosecond-Laser-Ablation Dynamics in Silicon Revealed by Transient Reflectivity Change. Micromachines 2022, 13, 14. [CrossRef] [PubMed]

28. Phillips, K.C.; Gandhi, H.H.; Mazur, E.; Sundaram, S.K. Ultrafast laser processing of materials: A review. Adv. Opt. Photon. 2015, 7, 684-712. [CrossRef] 
29. Lin, Z.; Hong, M. Femtosecond Laser Precision Engineering: From Micron, Submicron, to Nanoscale. Ultrafast Sci. 2021, 2021, 9783514. [CrossRef]

30. Yulianto, N.; Kadja, G.T.M.; Bornemann, S.; Gahlawat, S.; Majid, N.; Triyana, K.; Abdi, F.F.; Wasisto, H.S.; Waag, A. Ultrashort Pulse Laser Lift-Off Processing of InGaN/GaN Light-Emitting Diode Chips. ACS Appl. Electron. Mater. 2021, 3, 778-788. [CrossRef]

31. Yulianto, N.; Refino, A.D.; Syring, A.; Majid, N.; Mariana, S.; Schnell, P.; Wahyuono, R.A.; Triyana, K.; Meierhofer, F.; Daum, W.; et al. Wafer-Scale transfer route for top-down III-nitride nanowire LED arrays based on the femtosecond laser lift-off technique. Microsyst. Nanoeng. 2021, 7, 32. [CrossRef]

32. Juodkazis, S.; Nishimura, K.; Misawa, H.; Ebisui, T.; Waki, R.; Matsuo, S.; Okada, T. Control over the crystalline state of sapphire. Adv. Mater. 2006, 18, 1361. [CrossRef]

33. Liu, X.Q.; Chen, Q.D.; Guan, K.M.; Ma, Z.C.; Yu, Y.H.; Li, Q.K.; Tian, Z.N.; Sun, H.B. Dry-Etching-Assisted femtosecond laser machining. Laser Photonics Rev. 2017, 11, 3. [CrossRef]

34. Liu, X.Q.; Yu, L.; Chen, Q.D.; Sun, H.B. Mask-Free construction of three-dimensional silicon structures by dry etching assisted gray-scale femtosecond laser direct writing. Appl. Phys. Lett. 2017, 110, 091602. [CrossRef]

35. Liu, X.Q.; Yang, S.N.; Yu, L.; Chen, Q.D.; Zhang, Y.L.; Sun, H.B. Rapid Engraving of Artificial Compound Eyes from Curved Sapphire Substrate. Adv. Funct. Mater. 2019, 29, 1900037. [CrossRef]

36. Han, D.D.; Zhang, Y.L.; Ma, J.N.; Liu, Y.Q.; Han, B.; Sun, H.B. Light-Mediated Manufacture and Manipulation of Actuators. Adv. Mater. 2016, 28, 8328-8343. [CrossRef]

37. Zhang, Y.L.; Tian, Y.; Wang, H.; Ma, Z.C.; Han, D.D.; Niu, L.G.; Chen, Q.D.; Sun, H.B. Dual-3D Femtosecond Laser Nanofabrication Enables Dynamic Actuation. ACS Nano 2019, 13, 4041-4048. [CrossRef]

38. Wang, W.; Liu, Y.Q.; Liu, Y.; Han, B.; Wang, H.; Han, D.D.; Wang, J.N.; Zhang, Y.L.; Sun, H.B. Direct Laser Writing of Superhydrophobic PDMS Elastomers for Controllable Manipulation via Marangoni Effect. Adv. Funct. Mater. 2017, $27,1702946$. [CrossRef]

39. Huff, M. Recent Advances in Reactive Ion Etching and Applications of High-Aspect-Ratio Microfabrication. Micromachines 2021, 12, 991. [CrossRef]

40. Refino, A.D.; Yulianto, N.; Syamsu, I.; Nugroho, A.P.; Hawari, N.H.; Syring, A.; Kartini, E.; Iskandar, F.; Voss, T.; Sumboja, A.; et al. Versatilely tuned vertical silicon nanowire arrays by cryogenic reactive ion etching as a lithium-ion battery anode. Sci. Rep. 2021, 11, 19779. [CrossRef] 